The Practice of Promoting Primary Pupils' Autonomy: Examples of Teacher

Feedback

Eleanore Hargreaves, Institute of Education, University of London, 20 Bedford Way, London WC1H OAL

Tel: 07939586325

Email: e.hargreaves@ioe.ac.uk; eleanorehargreaves@hotmail.com

Word length: 7655 including references, abstract and tables

The paper has not been accepted and is not under consideration by any other journal. 


\section{The Practice of Promoting Primary Pupils' Autonomy: Examples of Teacher}

\section{Feedback}

\section{Structured Abstract}

\section{Background}

Some authors consider the ultimate purpose of Assessment for Learning to be the promotion of pupils' autonomy. But the concept of autonomy is problematic and teachers' attempts to promote autonomy in the classroom can seem both vague and impractical.

\section{Purpose}

In this paper, following Ecclestone (2002), I suggest that a full definition of autonomy includes children's independence, proactivity and critical inquiry in the classroom - which by their nature centre around the individual's capacity for self-directed learning and metalearning in their lives. I illustrate how one teacher promoted all three aspects of autonomy through her classroom feedback. Feedback is conceptualised as all the comments made by the teacher as a reaction to any activity or behaviour by pupils.

\section{Design and methods}

These examples draw on research data collected in 2009-11 in which nine 'profile' Year 5 [aged 9-10] children and their teacher were observed and interviewed about teacher feedback and ways in which it might promote autonomy. Five lessons across six months during 2010 have been analysed in detail, which were video-taped, audio-recorded, observed and followed up by interviews with individuals, pairs or threes from among the nine profile children.

\section{Findings}


Findings from this detailed analysis of lesson and interview transcripts suggested that the teacher employed a range of skilfully crafted autonomy-promoting feedback. Categories for this feedback consisted of the teacher feedback during the five lessons encouraging the pupil's: independence, usually in the sense of the child cultivating a view that might stand out from the general view [23 instances observed]; proactivity in learning, manifested through that child's unsolicited engagement with a topic [80 occasions noted]; metasocial critical inquiry, which was subdivided into: firstly, metasocial critical inquiry into rules about life including assessment [60 instances]; and secondly, metasocial critical inquiry into relationships, including social relationships occurring during learning collaboration [27 occasions]; and finally, most frequently, critical inquiry into learning processes [94 examples noted].

\section{Conclusions}

I conclude by noting that the teacher's feedback - whether intentionally or not - had the potential to inspire children's immediate and longer-term developments in independent learning, proactivity and critical inquiry.

\section{Key words}

Teacher feedback; autonomy; primary pupils; independence; proactivity; critical inquiry 


\section{The Practice of Promoting Primary Pupils' Autonomy: Examples of Teacher}

\section{Feedback}

Introduction

Marmot (2004) offers a compelling comment on autonomy, which provides a useful backdrop for this paper:

Autonomy- how much control you have over your life - and the opportunities you have for full social engagement and participation are crucial for health, well-being and longevity (2004, 2; my emphasis.)

The UNDP United Nations Development Development Programme (UNDP, 2014) used similar words to describe Human Development more generally:

A process of enlarging people's choices by expanding their ability to remain healthy, become educated, gain knowledge, enjoy decent standards of living, participate actively in community life and be creative in an environment of dignity and freedom (http://hdr.undp.org/en/select-a-theme).

Ecclestone (2002) defines learning autonomy to include pupils' independence, pro-active engagement and critical inquiry. The connotations of autonomy are that the individual can act independently of external authority and take the initiative for thinking and then acting as s/he sees fit; each individual senses an equal right to explore and express their own particular views, free from others' inhibiting judgements; and therefore has the ability to challenge habitual ways of thinking and traditional notions about his/her position in learning and/or in life. Thus independence, proactivity and critical inquiry are each closely aligned to a full definition of autonomy and, by their nature, centre around the individual's capacity for 
self-directed learning and meta-learning. Pryor and Crossouard $(2008,8)$ emphasise the critical aspect of autonomy as a specific aim of Assessment for Learning, including metasocial criticality. Within Assessment for Learning, there is:

... an explicit aim of raising students' critical awareness both of the discourses of the educational setting, and also of the wider social construction of these discourses... The pedagogic texts and the teaching context therefore become the object of critique, rather than functioning to 'deliver' knowledge.

These authors suggest that the importance of teachers promoting children's autonomy lies both in the benefits to children's learning attainments and in the more general development that accompanies such learning. Autonomy in these senses is not to be confused with the 'independence' pupils attain when they describe to an educational professional what level they are 'working' at in a prescribed educational framework and how they could attain the next level 'up'. In such performance-oriented assessment situations, students are trained in 'independent' procedures to achieve imposed instrumental goals, where the proactivity and the critical aspects of autonomy have been reduced. In contrast, the present research asked how the feedback of a classroom teacher had the power to promote a more comprehensive vision for children's learning which included autonomy. This research was undertaken against the backdrop described by James and Peddar (2006), who highlight the difficulties facing teachers' promotion of autonomy within the context of the performance orientation encouraged by recent educational policy in England.

Research on how verbal feedback can support learning in classrooms is currently sparse because this is a difficult area to pursue (although see Torrance and Pryor 1998; Brookhart 2001). With reference to Torrance and Pryor's spectrum from convergent to divergent 
assessment (1998), in providing convergent feedback, the teacher might confirm, reject, elaborate on or question a child's response. Alternatively, s/he might work more divergently by provoking a pupil independently to consider a concept with critical inquiry. It is this latter feedback that seems to have most potential for promoting pupils' autonomy. Feedback can, however, have side effects not designed by the feedback provider. In Torrance's (2012) words:

All assessment is formative, of student dispositions and self-identities as learners, as well as of knowledge and understanding, but not necessarily in a positive way (2012, 325)... Socio-cultural theory sees learning more in terms of apprenticeship rather than direct instruction $(2012,335)$.

The learner might be conceptualised as an apprentice who learns through feedback, not only the expert teacher's skills and knowledge but also about their attitudes, their ways of approaching work and their positioning in the wider community. Through these means, the learner's own dispositions and identity are formed. This is a broad-sweep conceptualisation of feedback, which challenges narrower traditional conceptions, but it may be referenced to the fact that children in primary school tend to look to their teacher as a valuable figurehead, whose commitment - they believe - goes beyond transmitting a national curriculum (Bibby 2009).

Such a view accords with Steinschott and Dobson's (2011) observation that some teacher feedback serves children's immediate learning, but other feedback becomes useful to them in the medium or longer term. In this sense it is conceivable that a teacher might make a comment that impacts on a student in a more or less positive way, later in their lives. The learner's overall diet of teacher feedback is likely to affect his/her abiding attitudes, 
approaches and positionings as well as immediate understandings within different domains. Where the teacher places high value on pupil autonomy, this diet is likely to embrace a higher proportion of autonomy-promoting feedback even when the teacher does not plan for this.

This paper aims to exemplify, from an observation of pupils in class and through talking with them, how autonomy can be promoted in a primary classroom of a state-funded school in England. To find vivid examples of this, I analysed the transcripts of five observed lessons and accompanying pupil interviews. I explored how the teacher's feedback seemed to promote autonomy in a range of ways, as well as how different children responded to autonomy-promoting feedback. This analysis therefore addressed the research question: What forms did autonomy-promoting feedback take in the five observed lessons?

\section{Research design}

\section{Methodological approach}

My epistemological stance for this study was informed by the principles of constructivism ( Cresswell, 2013; Hatch, 2002; Denzin and Lincoln, 2011), whose purpose is grappling with diverse social meanings. This study addressed the meaning the teacher and pupils ascribed to their experiences of feedback. The setting was therefore a natural setting:

... [which is] sensitive to the people and places under study, and data analysis is inductive and establishes patterns or themes. The final written report or presentation includes the voices of participants... (Cresswell, 2013, 14).

This constructivist approach to researching teacher feedback was most likely to allow insights into the subtleties of the teacher's widely ranging feedback and the children's diverse and sometimes unexpected responses. The data consisted of the words of the 
teacher and the children and its narration here aims to portray a vivid picture of the teacher's feedback but not to generalise implications from the findings. I assume that the findings may be relatable to many teachers' own practice and yet the setting will be different from all others. The study could therefore provoke in the minds of other researchers, teachers and policy makers further scrutiny of existing traditions of feedback and the promotion of autonomy through feedback. At the very least, it might provide what Bassey $(2001,5)$ called 'a powerful and user-friendly summary which can serve as a guide to professional action'.

Where other studies of feedback have sometimes used experimental conditions, this study was situated intentionally within a real classroom, operating as normally as is possible with a researcher present. The classroom tended to continue as it normally did when I arrived to collect data each week. In fact, my regular presence in the classroom over two terms meant that the children became used to me and as the months passed, seemed to notice me less. On the other hand, their frequent conversations with me about feedback apparently developed their awareness of this phenomenon over the months, allowing them to express some ideas more clearly.

\section{Research methods}

The research project took place between October 2009 and September 2011, with the aspects reported here constituting a sub-project which took place between January and July 2010. Ethical issues needed to be addressed carefully in this study because of the vulnerability of the children who participated in the research. The informed consent of all parents and all pupils was secured in writing, once full details of the project were made clear to them in the first instance. Initially, a few parents were worried that children were 
being 'used' for purposes of which they were unclear and expressed concern over disruptions that the video camera might cause. Additional information was therefore sent out, explaining the purposes of the project more fully. A guarantee was given that I would cease video-recording if it became a source of disruption, but this did not happen.In accordance with the ethical code followed (the British Sociological Association's code) and the requirements of the University's research ethics committee, anonymity was assured to all participants. Their names have therefore been obscured by pseudonyms in all publicised places.

The research methods I used were the video-taping and audio-recording of either literacy or mathematics lessons carried out once per week during two terms. On a rotational basis, a tiny audio-recorder was placed on a desk beside two profile children during the lesson so that their comments could be clearly discerned; while the teacher could also be heard. The microphone caused little noticeable disruption to lessons (although occasionally a child would make jokes into it). The teacher, under the pseudonym here of Mrs K, usually spent some time sitting with the group containing the particular children I was observing so that I was sure to record some individual feedback interactions with them.

These recordings were supplemented by audio-recorded individual, paired or threesome post-observation interviews during which the participant pupils viewed the video-tape of their lesson. In interview, I played the video to them, pausing at each feedback episode and asking the children to tell me about what was going on, asking for example, 'What did you think/feel when the teacher told you that...?' or 'Why did she say that to you, do you think?' Subsequently, for ethical reasons, I deleted the video footage, which was used as an interview stimulus only and not for further analysis. 
In the project as a whole, 16 hours and 35 minutes of audio-recorded interview occurred with nine profile pupils. Each profile pupil was interviewed three times following videorecorded lessons between January and July 2010. The exceptions were: pupil Josh who was interviewed four times overall and pupils Aaron and Maddie who were interviewed only twice. Each child was additionally interviewed individually about their general views on school, without the stimulus of any video-film (reported elsewhere in Hargreaves 2012). Each video-recorded lesson was also observed, and notes taken which simply set the scene for understanding the recordings.

For the sub-project reported here, however, only five of the recorded lessons were analysed, plus their accompanying interviews and the teacher interview. The five lessons were selected because they were representative of the full set of transcripts, they were complete lessons of between 35 and 50 minutes and they focused on each profile child at some stage. The five pupil interviews involved different profile children each time, except that pupil Laila appeared in two (see Table 1). Two interviews focused on the 'high' attainers, two on the 'low' attainers and one on the 'middle' group. Details are provided in Table 1.

\section{Table 1 here.}

For each of the five selected lessons, the transcript of the lesson was scrutinised in great detail, in relation to the teacher's words. The transcript of the interview conducted afterwards was also interrogated and the two transcripts were compared to throw light on each other's meanings. The results presented below are based on the themes that emerged by investigating both sets of transcripts, as well as the transcript from a teacher interview 
carried out later. Only one teacher interview was carried out because the focus of the project was on pupils' voices.

Mrs K was interviewed after two articles had been written about this whole project. She was asked her overall impression of the children's comments in this research; whether my interpretations were justified; whether the findings surprised her; what it was is like for her, when I was carrying out this research; and whether anything had arisen that might be useful to her in her teaching. Any comments she made that related to feedback and autonomy were noted and have been reported in this paper.

\section{The children}

The nine profile children were selected on the basis of some initial group interviews with everyone in the class in December 2009 (reported elsewhere in Hargreaves 2012). Five girls and four boys were selected as profiles in consultation with Mrs K. They spanned the range in terms of National Curriculum Attainment Levels [NCL] used in England, with three attaining lower levels (Dave, Laila and Wayne), four attaining highest levels (Aaron, Esther, Josh and Mia) and two who were considered average (Farhana and Maddie).

I have referred to their attainment levels as related specifically to NCL; this is in order to avoid suggesting that these levels reflected their competence in a more general sense. The practice of seating pupils in attainment groups was common across Mrs K's school. Rather than having 'ability sets' for the whole class or whole subjects, at that time the school used attainment groups within a mixed-ability classroom. This grouping was not entirely rigid, although for literacy and mathematics it tended to be more fixed than for other curriculum subjects. Even in mathematics, however, on one occasion I saw a 'middle' NCL child work with the 'higher' NCL children to see how she would cope. In conversation with me, 
teachers in that school made comments suggesting that such groupings were the obvious way to make differentiation of classwork easier for the teacher. The children seemed to be acutely aware that they were grouped according to attainment, even though Mrs K never referred to the groupings as such. For example, the children referred to the fact that lower attainers received more attention - including more directive answers to challenges - during class time than the other groups because they needed more help. The school's emphasis on keeping exact records of pupils' attainment in the core subjects meant that it was easy for Mrs $\mathrm{K}$ to determine the groupings. Although Mrs K did not like the idea of dividing her time unfairly, she did not challenge the basic assumption that attainment grouping was helpful but she did not acknowledge differentiating her feedback depending on attainment.

The research school

This school was selected because it was considered to be thriving, with a history of good OFSTED reports (OFSTED is the Office for Standards in Education, Children's Services and Skills, responsible for carrying out school inspections in England). The head teacher suggested that I worked in Year 5 (the year group with children aged 9 to 10) with Mrs K because Mrs K was a competent and confident teacher. Her experience of teaching had been in the same school since she qualified, seven years previously. Like all the teachers in this school, she had received training from the local authority in using Assessment for Learning strategies. The principles of Assessment for Learning, in particular its role in promoting autonomy, had not been emphasised, however, and although she valued each child's individuality she was understandably unwilling to work 'against the grain' or to upset authorities by trying something risky. She agreed to take part in this study, more because she was willing to learn than out of particular interest in exploring the topic. Initially she 
resisted the idea of the video-camera in her class but was reassured when it was positioned to focus on the children rather than on herself. She did freely give consent for findings from this research to be submitted for publication but on reading the scripts of articles written about her teaching, she became a little perturbed when children described having negative emotions as a result of her feedback: for example, when Laila and Dave expressed fear of her disapproving look. She was pleased that her feedback helped children to understand some concepts better, but she did not anticipate investigating their responses in the future.

\section{Analysis}

The five selected lessons were analysed using handwritten notes which were made on the five observation transcripts and the related interview transcripts. Codes were written on the left-hand side of the transcript page if the teacher's feedback seemed to be nonautonomy promoting. These codes often reflected Torrance and Pryor's (1998) notion of feedback within a 'convergent' assessment approach, in contrast to feedback within a 'divergent' assessment approach which had more similarities with the 'autonomypromoting' category. The non-autonomy promoting codes were subdivided into the following, as shown on Table 2.

The non-autonomy promoting categories consisted of the teacher feedback encouraging the pupil's:

- Continuation or cessation of a particular activity. In this case, the teacher shows approval or disapproval, e.g. Mrs K said, 'Oh! I like that' to show approval and 'Oh, grrrr!' to indicate disapproval. This category accorded with Gipps et al's (2000, p.92) evaluative feedback category of 'expressing approval and disapproval'. It 
potentially affected future behaviour but its links to what was in the teacher's mind, unexplained to the child, made its promotion of autonomy unlikely and unevidenced;

- Correct answer. The teacher asks a closed question, which is sometimes disguised as an open one, e.g. she asked the closed question during literacy, 'It's an adverb because it ends in....?' and also, a closed question disguised as an open one, 'What do you think?' when the issue was how to spell 'stinky';

- Feelings of shame or pride. Mrs K commented on the pupil self, e.g. she told Aaron, 'You rush through things - you're a bright lad, you're all very bright on this table... but you mustn't rush.' This is the feedback that Hattie et al (2007) suggested might be destructive to learning because involvement of the ego distracts the learner. Although for some pupils, shame or pride could induce action, pupil behaviour in this study suggested their action was teacher-directed rather than for the pupil;

- Certainty about correctness. The teacher confirms that an answer is right e.g. 'You're absolutely right'. This reassuring feedback resonates with Gipps et al's (2000, p.92) category of descriptive feedback named 'telling children they are right'. Whilst this feedback did seem to reassure pupils, there were no suggestions that it directly promoted autonomous actions;

- Increased understanding. The teacher repeats or explains an answer, sometimes elaborating extensively, e.g. Mrs K repeated a pupil's answer: “Five frisky foals'... they link together, those two words, don't they, because often, foals are described as being frisky'. On another occasion, even though Wayne had demonstrated a 'glimpse' convincingly, she proceeded to elaborate, '... it's not stop and have a look, 
is it? It's like Wayne said, you just glance at it, then you choo-choo by'. Whilst increased understanding could potentially lead to increased autonomy, it seemed that this was the case mainly when such feedback was specifically solicited by the learner;

- Grasp of the correct answer. The teacher provides or pre-empts an answer, e.g. she asked Laila why she had to put an extra piece of wood into the catapult she was making; before Laila could answer, Mrs K intercepted, 'It was because the cam, the cam on the shelf, wasn't wide enough'; and

- Action. The teacher instructs a pupil to act, as her feedback, e.g. in response to Josh telling her that he got the first test question right, she responded, 'Let's keep going'. Usually this feedback had some managerial dimension in terms of redirecting pupils' attention.

Within these categories, little feedback was directed at 'self' [3 instances] thus pupils' attention was rarely diverted to their ego through feedback. Mrs K's most common nonautonomy promoting feedback was to ask closed questions [313 instances]. She confirmed a child's answer was right very frequently too [296 instances] and she seemed to have a tendency to elaborate extensively. Mrs K also frequently showed her approval or disapproval [155 instances], gave instructions as feedback [104 instances] and provided answers [91 instances].

Feedback assumed to be autonomy-promoting was noted in the right-hand margin of the transcript page. This feedback reflected the attributes that Dweck (2006) associated with a 'growth mindset'. The categories (see Table 2) consisted of the teacher feedback encouraging the pupil's: 
- Independence, usually in the sense of the child cultivating a view that might stand out from the general view [23 instances observed];

- Proactivity in learning, manifested through that child's unsolicited engagement with a topic [80 occasions noted]. Mrs K sometimes encouraged proactivity using humour;

- Metasocial critical inquiry, which was subdivided into: firstly, metasocial critical inquiry into rules about life including assessment [60 instances]; and secondly, metasocial critical inquiry into relationships, including social relationships occurring during learning collaboration [27 occasions]; and

- Critical inquiry into learning processes [94 examples noted].

\section{Table 2 here.}

I assembled all the autonomy-promoting sentences or phrases in specific lists together, in addition to coding and counting them. The codes were developed by reading and rereading the transcripts, trying to decide with an inductive approach how feedback examples were intended and experienced and how they influenced pupils' learning. This was done by consideration of the teacher's and pupils' own words and the research literature.

During the first read-through of the five observation transcripts and the accompanying interview transcripts, the codes were developed. A feedback instance was coded if the teacher appeared to have one intention in her feedback; if she repeated feedback with the same intention in the same sentence, then this was coded as one instance. If however, she demonstrated two different intentions through two different feedback instances within the same sentence, then these were classified as separate. Feedback was defined for coding purposes as any response from the teacher to a pupil's behaviour or action. This meant 
that, in a fairly teacher-centred, but interactive lesson, much of the teacher's talk was coded as feedback.

During a second reading, these codes were applied and during a third, their contexts and finer details were explored. This application and exploration were helped by my noting the teacher's usual tendency and relating this to problematic instances, based on two terms' worth of my weekly observations in her classroom, and the tone of her voice on audio-tape. The pupils' responses to her feedback could also help ascertain which code to give it. For example, Mrs K. told Esther, 'See if you can add some words to make it make sense'. This feedback might have been considered to promote critical inquiry into learning. On the other hand, it could have been used by Mrs. $\mathrm{K}$ as an instruction to distract her towards a different behaviour. Esther's response illustrated that it functioned as the first of these, because she said pensively, 'I was trying to think, because I didn't really know...' There were very few occasions, however, on which two different codes had to be considered, as in most cases the coding seemed obvious during the final analysis.

\section{Examples of autonomy-promoting feedback}

\section{Independence}

Independence was defined as the pupil expressing a view or answer that suggested original thought. It was however the least-used autonomy-promoting feedback code used in the five lessons [23 instances]. Independence-promoting feedback encouraged the children not just to guess the answer in the teacher's head but to come up with something original. For example, Mrs K told Farhana [middle NCL] as she wrote her non-chronological report about the Aztecs, 'Don't write something that l'm saying just for the sake of it...' and commented that Farhana had given some '...nice facts, certainly something I didn't know about.' Mrs K 
applauded Laila [lowest NCL] for using the unusual word 'wonky' in her report about making a wooden catapult. She showed genuine openness to Dave [lowest NCL] when she asked him for his review of making wooden catapults: 'Tell me one thing that you liked about this project... or maybe [you] didn't enjoy?' And Dave [lowest NCL] was later seen to be standing his ground against the teacher, arguing against the teacher's suggestion that his gluing was at fault in making the catapult. He gave a show of splendid independence - unless it was resistance borne out of his sense of dependence.

During interviews, it transpired that the profile children were cautious of expressing their independent opinions at school. Laila [lowest NCL] and Farhana [middle NCL] recounted how they grew more confident in expressing their independent views during research interviews as the months passed. Laila summed this up: 'I learnt to, like, to tell the truth and not to keep it bottled up'. Esther [highest NCL] admitted that she used to 'twist the truth' a bit to start with, until she realised that I really wanted to know what she thought. In research interview, however, perhaps it felt safer to express an autonomous view than in the public arena of the classroom. Thus using feedback to develop children's confidence to hold a unique view appeared to be an area for development within the classroom, which perhaps flies in the face of the traditional view of the teacher as the prime Knowledge Giver (Linn 2007).

\section{Proactivity}

Promoting proactivity was a frequently coded autonomy-promoting feedback in the five lessons [ 80 instances]. The teacher's feedback categorised as encouraging proactivity included those occasions on which Mrs K's main purpose for an utterance was to promote 
deeper engagement with a topic or to motivate a child without providing praise. Mrs $\mathrm{K}$ seemed to use four distinct strategies:

1) Encouragement through reassurance. For example, she said to Farhana [middle NCL] whilst writing: 'Just cross it out and write it above it, okay? Don't worry about it too much'. And she told Josh and Aaron [both highest NCL] when they could not understand a mathematics concept, 'That's all right, we'll talk it through... that's fine'. These comments encouraged them to keep going and not to lose spirit. In her interview, Mrs K suggested that being gentle with pupils was important for their confidence to make inquiries:

If they like somebody they'd be willing to speak to them if they need help or something... I would hate for any child to think, you know, that I'm scary or something like that.

2) Encouragement through humour. It transpired that Mrs K used humour with higher NCL groups (although it never manifested itself with the lowest NCL) as a way to encourage them to keep engaging. For example, when discussing the Aztecs she was heard to say: 'Great, a game where you get killed. Fabulous! (Farhana [middle NCL] laughs.)' During the lesson on alliteration she made such comments as: '[Laughs] Thank you very much!... yeah, I can't imagine a little diddly ant feasting on an ape.' Sometimes the pupils responded to her with their own jokes and Aaron [highest NCL] was explicit in interview that 'jokey' feedback helped him to engage. It was intriguing that Mrs K was never observed to use humour with lower NCL groups even though the three lowest NCL children made plenty of jokes with me during research 
interviews. Perhaps Mrs K was worrying about covering the desired content with this group which seemed to make time limited for joking.

3) Encouragement through challenging. Mrs K found each group of children mini-tasks to achieve, looking ahead to the promise of success in the future. For example, she challenged her highest NCL as they worked on similes: 'Find a simile... then see if you can find another one. I'll see how many I can find.' She told Aaron [highest NCL] she was intrigued to know how his sentence would end, which inspired him to write a striking finish ('Two horrid hungry horses hanged hay hilariously from their head').

4) Encouragement through responding to children as individuals. Mrs K had a knack of responding to children in a personal way, to engage them at individual level. She was heard to say, for example: 'That's quite interesting!' and 'Let's ask Mia then, since she's trying to put her hand up more...' (and Mia [highest NCL]'s response was 'Oh yay!'). Mrs K even referred to her own individual weakness, as she fed back on Esther [highest NCL]'s claim that Mrs K never worked with her group: 'My goodness, that's an awful thing to say. Okay, l'd better work with you.' In this way, she seemed to legitimise children as valuable individuals, not just parts of a group.

During observations and interviews, the children did make comments which suggested their proactive engagement, and this applied particularly to Wayne and Laila [both lowest NCL] in relation to studying the poem 'From a railway carriage'. Wayne was sometimes better at making his own unsolicited (and often astute) observations than answering the teacher's questions. I saw him interrupt the teacher because he had a different understanding of rhyme compared with hers. He exclaimed:

Wayne: All of them could rhyme. 
Teacher: Are you saying "bridges" rhymes with..?

Wayne: There is "E-S," "E-S," "E-S," "E-S."

Teacher: Do all those words rhyme, Wayne? Does "fairies" rhyme with "witches?" Wayne, does "fairies" rhyme with "witches," for example?

(Pause.)

Wayne: No. But they...

It seemed here that Wayne was earnestly struggling to understand what 'rhyme' meant, yet he was a child who claimed to hate literacy. Thus Mrs K's strategies for promoting proactivity might have contributed to his unsolicited inquiry which he pursued with notable determination both during class and in interview afterwards.

\section{Meta-social inquiry}

Perhaps meta-social inquiry-promoting feedback is the area within which autonomy is most clearly promoted. Bibby (2009) described a primary teacher who did not believe her job related to meta-social issues, only to cognitive ones. Mrs K, however, clearly believed that her feedback played a role in children's learning about meta-social issues.

Mrs K provided frequent feedback comments [60 instances] encouraging thought into life inside and outside the classroom. Mrs K helped the pupils make clearer the link that they seemed to find mysterious, the link between schoolwork and life as adults beyond school. For example, she fed back on what she thought might happen if they did not study design and technology: 'If you need to put a screw in the wall... at the age of say $25,30 \ldots$ you'd be pretty stuffed wouldn't you?' 
In the poetry lesson, she tried to give her class a feeling for the standards that might be appropriate for Year 5 children (aged 9 to 10 years), telling them: 'That's quite hard, that's quite deep, I think, for Year 5 children to talk about that!' Mrs K also directed the children to look flexibly for guidance from any tools available in the classroom, such as displays on the walls, notes on the white board and objects that were lying around. She explained: You can use tools, for example a ruler, to work out right angles, not for measuring. ...You've got a number line straight away... So you've got your subtraction going, okay?

One key feature of Assessment for Learning has been described by Wiliam as activating students as instructional resources for one another $(2011,4)$. Mrs K's feedback emphasised the value of doing just that in 27 instances observed. For example, she would feed back about completed work, 'I'm going to ask you to share what you've written, Okay?' or on another occasion, 'I'm going to ask you to give her a suggestion to make it even better'. Sometimes Mrs K fed back that the children should discuss a topic, thus encouraging them to give feedback to each other informally. For example, she was heard to say on several occasions, 'Chat with the people on your table about how you work things out...'. Beyond that, her message seemed to be that working as a team was a desirable goal in itself. She seemed to feed back to the children that everyone should have an equal chance in this team and make an equal contribution. She reprimanded one child for not contributing to the whole class discussion and told another child not to disturb the class with silly noises. This feedback related to her meta-social message that each individual was valuable as a person. She explained in interview, 'If we do work well, fantastic, but I would rather a better person that doesn't work so well...than someone who doesn't really care about anyone.' A chance 
comment was picked up on the audio-tape, whereby Mrs K suddenly turned to the teaching assistant in her class and exclaimed, 'Hello by the way, and thank you for being here!' Perhaps this feedback would linger in the children's minds as a model for relating to other people.

In interview, Mrs K recognised that the children were socially aware, in that they were sensitive to her feelings. She said:

The [children] didn't want to be identified if they said something [negative about me] and then it got back to me, and that was really lovely.... it's great to be liked.

The pupils were also aware of social injustice in feedback. For example, in interview Laila [lowest NCL] told me she received the feedback that she was allowed to write in print; but Dave [lowest NCL] was told to join his letters. However, during the same interview, Dave attributed this injustice to some non-egalitarian views about boys being best at being messy and watching TV while girls were best at being neat. Perhaps this was an area ripe for provocative questioning.

\section{Critical inquiry into learning processes}

Mrs K's feedback supporting critical inquiry into learning processes consisted of 94 general and specific statements about what might help the children's learning, including their learning in their futures. This was the most commonly coded autonomy-promoting feedback of all. As an example, Mrs K intimated a couple of times that 'having a go' was a 'good thing', hinting that 'having a go' required children to be careful in how they went about a new task. She told the highest NCL group: 'You really need to think about where you're sitting [to learn best]'. And she fed back, 'If you can work out where someone's gone wrong, that makes you even cleverer than just getting it right yourselves.' 
Mrs K modelled a selection of open questions as her feedback with the aim of prompting thinking about learning. For example, she would feed back on a child's performance, 'What else?' and 'If you could do it a second time, what would you do differently?' Sometimes she pursued the children's answers with additional feedback, persisting for example with: 'And what did you learn from it?' She modelled authentic inquiry as feedback, when she was herself perplexed as to whether there were metaphors in a poem or not. She responded to Laila [lowest NCL]'s query as to whether there were metaphors in it with: 'What do you think? Is there any? Is there any?' and she deliberated aloud about her quandary before asking me as researcher for advice.

A few instances of Mrs K's feedback related specifically to the benefits of self-regulation. She encouraged the children's own inquiry or self-assessment into learning. For example, she suggested children use white boards so they could make improvements as they went along. She fed back to them at points across the lesson:

Going through these questions, tell me one thing you think, "Oh, I know what to do next time. If I had another chance, I know what l'd do next time."

There were examples of the children self-regulating, sometimes just taking the opportunity to work out a puzzle. Esther, Josh and Mia [all highest NCL] knew where they had become confused with a mathematical operation. I heard Josh say: 'I always get them mixed up. I should have looked on my learning cards'. Mia had worked out that: 'Sometimes when I'm under pressure I don't do as well. I concentrate so hard that I sometimes do it wrong'. Maddie [middle NCL] was able to articulate that she needed to be 'in the zone' to learn deeply, that if she were bored she would mess around, but if she 'really' tried, then she 
would make progress. These statements suggested that the pupils had been provoked to reflect on how they learnt.

At other times the children talked about their particular weaknesses in relation to specific areas. For example, Farhana [middle NCL] realised she would have made fewer mistakes if she had checked her writing work through and Josh [highest NCL] knew he needed to read the [test] question more carefully.

\section{Concluding thoughts}

This research addressed the research question: What forms did autonomy-promoting feedback take in the five observed lessons? Findings from this detailed analysis of lesson and interview transcripts suggested that the teacher employed a range of skilfully crafted autonomy-promoting feedback. Categories for this feedback consisted of the teacher feedback during the five lessons encouraging the pupil's: independence, usually in the sense of the child cultivating a view that might stand out from the general view; proactivity in learning, manifested through that child's unsolicited engagement with a topic; metasocial critical inquiry, which was subdivided into: firstly, metasocial critical inquiry into rules about life, including assessment; and secondly, metasocial critical inquiry into relationships, including social relationships occurring during learning collaboration; and finally, critical inquiry into learning processes.

In a society where academic qualifications no longer guarantee work, work no longer promises security and changes happen increasingly fast, the individual's sense of autonomy - and the capacity for autonomous learning that it embraces - has increased currency. Within this framework, an individual's independent voice, their proactivity and their capacity for critical metasocial and cognitive inquiry play important roles in the extent to 
which they thrive (Ecclestone, 2002). Independence, proactivity and the capacity for critical inquiry are all closely related to how much control and choice a person has over their life and the opportunities they face for full social engagement in a fluid society (Marmot, 2004). Autonomy in these senses underpins a person's development of their full potential and their active participation in community life where they can be creative in an environment of dignity and freedom (UNDP, 2014).

The results of this research in one classroom illustrate the potential for the class teacher to support pupils in managing both immediate and longer-term needs, in terms of meeting classroom learning targets as well as nurturing the child's identity as an autonomous actor (Steinschott and Dobson 2011). The results also exemplify that pupils seemed to take on board the range of messages implied by the teacher, whether she was aware of how they understood them or not (Torrance, 2012). The child who is encouraged to keep considering different ways of arriving at answers and to share ideas and mistakes with peers, for example, may well experience this encouragement as feedback which ultimately leads to a critical and inquiring approach towards learning and learning situations. The teacher who tends to approach feedback with a divergent - rather than a convergent - assessment purpose, is likely to support rather than to undermine the child's capacity for autonomous inquiry (Torrance and Pryor, 1998), raising pupils' critical awareness both of the discourses within the educational setting, and also of the wider social construction of these discourses (Pryor and Crossouard, 2008, 8).

What is also highlighted by this study is the need to carry out more extensive and more intensive research into teachers' verbal feedback and into how children perceive it and respond to it. In particular, some differences between how the teacher feeds back to 
different attainment groups could usefully be explored further, because the pupils in this study hinted that 'low attainers' received different - less autonomy-promoting - feedback compared with other groups. This research suggests that teachers need to keep nurturing and monitoring their awareness of how any comment they make may contribute to children's immediate and longer-term developments in independent learning, proactivity and critical inquiry.

\section{Acknowledgements}

Many thanks are due to the patient Mrs K and the children who took part in this research as well as to the school who accommodated me. Thanks are also due to David Halpin who gave me feedback on an earlier draft of this paper. 


\section{References}

Bassey, M. 2001. "A Solution to the Problem of Generalisation in Educational Research: Fuzzy Prediction". Oxford Review of Education 27: 5-22. Doi: 10.1080/03054980123773

Bibby, T. 2009. "How do Children Understand Themselves as Learners? Towards a Learner-centred Understanding of Pedagogy". Pedagogy, Culture \& Society 17 (1): 41-55. Doi:10.1080/14681360902742852

Brookhart, S. 2001. "Successful Students' Formative and Summative Uses of Assessment Information". Assessment in Education 8: 153-169. Doi: 10.1080/09695940123775 Creswell, J. W. 2013. Qualitative Inquiry and Research Design: Choosing Among Five Approaches. Third Edition. London: Sage.

Dweck, C. 2006. Mindset: The New Psychology of Success. New York: Random House. Ecclestone, K. 2002. Learning Autonomy in Post-16 Education. London: RoutledgeFalmer. Gipps, C., B. McCallum and E. Hargreaves. 2000. What Makes a Good Primary School Teacher: Expert Classroom Strategies. London: RoutledgeFalmer.

Denzin, N. and Y. Lincoln. 2011. The SAGE Handbook of Qualitative Research. London: SAGE. Hargreaves, E. 2012. “Teachers' Classroom Feedback: Still Trying to Get it Right". Pedagogies 7 (1): 1-15.

Hatch, A. 2002. Doing Qualitative Research in Education Settings. New York: SUNY Press. Hattie, J. and H. Timperley. 2007. "The Power of Feedback". Review of Educational Research 77: 81-122. Doi: 10.3102/003465430298487 
James, M. \& D. Peddar. 2006. “Beyond Method: Assessment and Learning Practices and Values". Curriculum Journal 17 (2): 109-138. Doi.org/10.1080/09585170600792712 Lin, A.M. 2007. “What's the Use of 'Triadic dialogue?': Activity Theory, Conversation Analysis, and Analysis of Pedagogical Practices". Pedagogies: An International Journal, 2 (2): 77-94. Doi: 10.1080/15544800701343943

Pryor, J., \& B. Crossouard. 2008. "A Socio-cultural Theorisation of Formative Assessment". Oxford Review of Education 34 (1): 1-20. Doi: 10.1080/03054980701476386

Marmot, M. 2004. "Status Syndrome: How your Social Standing Directly Affects your Health and Life Expectancy". Significance 1 (4): 150-154. Doi: 10.1111/j.1740-9713.2004.00058.x Torrance, H. 2012. "Formative Assessment at the Crossroads: Conformative, Deformative and Transformative Assessment". Oxford Review of Education 38 (3): 323-342. Doi: $10.1080 / 03054985.2012 .689693$

Torrance, H., \& J. Pryor, J. 1998. Investigating Formative Assessment. Buckingham: Oxford University Press.

Steinschott, R. \& S. Dobson, eds. 2011. Introduction to an Opaque Educational Landscape. Norway: Bildung.

United Nations Development Programme (UNDP). 2014. http://hdr.undp.org/en/select-atheme

Wiliam, D. 2011. "What is Assessment for Learning?" Studies in Educational Evaluation 37 (1): 3-14. Doi.org/10.1016/j.stueduc.2011.03.001 
TABLE 1. Five lessons observed and transcribed, accompanied by post-observation interviews with the full range of profile children

\begin{tabular}{|c|c|c|c|}
\hline $\begin{array}{l}\text { Date and } \\
\text { length of } \\
\text { observed } \\
\text { lesson }\end{array}$ & Subject of lesson & $\begin{array}{l}\text { Structure of } \\
\text { lesson: teacher } \\
\text { focussing on }\end{array}$ & $\begin{array}{l}\text { Profile pupils interviewed } \\
\text { afterwards about feedback in } \\
\text { the lesson }[\mathrm{NCL}]\end{array}$ \\
\hline $\begin{array}{l}\text { January, } \\
45 \text { mins }\end{array}$ & $\begin{array}{l}\text { Literacy: practising use of } \\
\text { alliteration. }\end{array}$ & $\begin{array}{l}\text { Whole class then } \\
\text { small group. }\end{array}$ & Esther [highest NCL] \\
\hline $\begin{array}{l}\text { February, } \\
37 \text { mins }\end{array}$ & $\begin{array}{l}\text { Mathematics: practice } \\
\text { maths test feedback } \\
\text { session. }\end{array}$ & $\begin{array}{l}\text { Whole class then } \\
\text { small group. }\end{array}$ & $\begin{array}{l}\text { Aaron, Josh and Mia [highest } \\
\mathrm{NCL} \text { ] }\end{array}$ \\
\hline $\begin{array}{l}\text { March, } \\
35 \text { mins }\end{array}$ & $\begin{array}{l}\text { Literacy: writing a non- } \\
\text { chronological report } \\
\text { about the Aztecs. }\end{array}$ & $\begin{array}{l}\text { Two individuals, } \\
\text { one after the } \\
\text { other. }\end{array}$ & $\begin{array}{l}\text { Ferhana and Maddie [middle } \\
\mathrm{NCL} \text { ] }\end{array}$ \\
\hline $\begin{array}{l}\text { Early May, } \\
50 \text { mins }\end{array}$ & $\begin{array}{l}\text { Literacy: exploring poetic } \\
\text { devices in a poem, and } \\
\text { whether children liked it } \\
\text { and when they thought it } \\
\text { was written. }\end{array}$ & $\begin{array}{l}\text { Small group then } \\
\text { whole class. }\end{array}$ & Wayne and Laila [lowest NCL] \\
\hline $\begin{array}{l}\text { Late May, } \\
50 \text { mins }\end{array}$ & $\begin{array}{l}\text { Literacy: reflecting on } \\
\text { benefits and problems } \\
\text { with DT project. }\end{array}$ & $\begin{array}{l}\text { Whole class then } \\
\text { pair of pupils. }\end{array}$ & Dave and Laila [lowest NCL] \\
\hline
\end{tabular}


TABLE 2. Feedback analysis codes

\begin{tabular}{|c|c|}
\hline CODE & DESCRIPTION OF CODE \\
\hline $\begin{array}{l}\text { ASSUMED TO BE NON- } \\
\text { AUTONOMY PROMOTING. }\end{array}$ & Feedback given to encourage the pupil's: \\
\hline APPROVAL OR DISAPPROVAL & Continuation or cessation of particular activity \\
\hline $\begin{array}{l}\text { CLOSED QUESTION [+ } \\
\text { SOMETIMES DISGUISED AS } \\
\text { OPEN] }\end{array}$ & Correct answer \\
\hline PUPIL SELF & Feelings of shame or pride \\
\hline CONFIRMS ANSWER IS RIGHT & Certainty about correctness \\
\hline $\begin{array}{l}\text { REPEATS OR EXPLAINS } \\
\text { ANSWER [+ ELABORATES } \\
\text { EXTENSIVELY] }\end{array}$ & Increased understanding \\
\hline $\begin{array}{l}\text { PROVIDES OR PRE-EMPTS } \\
\text { ANSWER }\end{array}$ & Grasp of the correct answer \\
\hline $\begin{array}{l}\text { INSTRUCTION AS REACTION } \\
\text { TO PUPIL RESPONSE OR } \\
\text { BEHAVIOUR }\end{array}$ & Action \\
\hline \multicolumn{2}{|c|}{ ASSUMED TO BE AUTONOMY-PROMOTING. Feedback given to encourage the pupil's: } \\
\hline INDEPENDENCE & Cultivation of view that stands out from the general view \\
\hline $\begin{array}{l}\text { PROACTIVITY [+ USING } \\
\text { HUMOUR] }\end{array}$ & Unsolicited engagement \\
\hline $\begin{array}{l}\text { METASOCIAL CRITICAL } \\
\text { INQUIRY } \\
\text { INTO LIFE [+ ASSESSMENT] }\end{array}$ & Metasocial inquiry into rules about life and/or assessment \\
\hline $\begin{array}{l}\text { METASOCIAL CRITICAL } \\
\text { INQUIRY INTO RELATIONSHIPS }\end{array}$ & $\begin{array}{l}\text { Metasocial inquiry into social relationships, including } \\
\text { learning-collaboration }\end{array}$ \\
\hline
\end{tabular}


